\title{
STUDY ON MONITORING AND EARLY WARNING OF KARST COLLAPSE BASED ON BOTDR TECHNIQUE
}

\author{
Z.D. Guan
}

School of environmental studies, China university of geosciences, Wuhan, Hubei 430074, China

Institute of Karst Geology, CAGS, Qixing 50 Rd., Guilin, GuangXi, 130026, P.R. China, guanzd@karst.ac.cn

\section{X.Z. Jiang}

Institute of Karst Geology, CAGS, Qixing 50 Rd., Guilin, GuangXi, 130026, P.R. China, @karst.ac.cn

\section{Y.B. Wu}

Institute of Karst Geology, CAGS, Qixing 50 Rd., Guilin, GuangXi, 130026, P.R. China, @karst.ac.cn

\section{Z.Y. Pang}

Institute of Karst Geology, CAGS, Qixing 50 Rd., Guilin, GuangXi, 130026, P.R. China, @karst.ac.cn

\begin{abstract}
Brilliouin Optical Time Domain Reflectometer (BOTDR) is a newly developed measurement and monitoring technique, which utilizes Brilliouin spectroscopy and Optical Time Domain Reflectometer (Jiang et al., 2006; Zhang et al., 2009; Xu et al., 2011) to measure strain generated in optical fibers as distributed in the longitudinal direction. This paper introduces the principle and characters of BOTDR technique firstly, and makes an example of karst collapse monitoring at section K14 of highway from Guilin to Yangshuo. Discussion includes how to use this technique in underlying karst collapse monitoring in karst highway; environmental factors, like temperature and vehicle dynamic load; how to affect the monitoring results; and how to choose optical fiber type and paving region. At last, we compare the results between using BOTDR and geological radar, and conduct the safety diagnosis on the experimental road. The application achievements demonstrate that BOTDR is a viable technique for the karst collapse monitoring.
\end{abstract}

\section{Introduction}

Brillouin Optical Time Domain Reflectometer (BOTDR) is a new-type photoelectric monitoring technique. Using spectrum technology and optical time domain measuring technology, BOTDR technique takes optical fiber as a monitor to incessantly measure the external physical parameter located along the geometric path of optical fiber and gain the changing spatial- temporal property of the measured object in order to realize the monitoring on the deformation of rock-soil body. Compared with traditional measuring methods, optical fiber can serve as conductive medium as well as sensing medium. Meanwhile, the features of optical fiber texture such as explosion proofing, anti-electromagnetic interference, resistance to corrosion, heat-resistance, small size and light weight allow the implementation of long-distance measurement, so it is more adaptive to severe environment. At present, a large number of studies have been done on structural engineering and geotechnical engineering field, both at home and abroad, and many technology inventions and significant progress have been made (Linker et al., 2009; Assaf et al., 2010). However, there are not many studies aiming at monitoring karst soil caves. The karst collapse event is uncertain and elusive in space, and abrupt in time. Traditional monitoring methods mainly use means such as groundwater dynamic conditions monitoring and regular geophysical prospecting, which cannot realize long-term regional monitoring. While the features of BOTDR technique allow the possibility of automatic, networked, and regional monitoring and early warning. Combined with the highway construction from Guilin to Yangshuo our research group started the study with BOTDR technology for monitoring and early warning of karst collapse so as to better apply BOTDR technique to karst collapse monitoring and early warning.

\section{The basic principle of BOTDR monitoring}

The BOTDR basic principle is the utilization of the linear relation between: the frequency shift change of Brillouin scattering light in optical fiber and the axial strain received by the optical fiber; and the obtainment of the axial strain of the optical fiber (Shi et al.,2005; Liu et al,1998; Haruyoshi et al,1997; Figure 1).

The drift distance between axial strain of optical fiber and the frequency of Brillouin scattering light is showed by formula (1) below:

$$
\mathrm{V}_{\mathrm{B}}(\varepsilon)=\mathrm{V}_{\mathrm{B}}(0)+\frac{\partial \mathrm{V}_{\mathrm{E}}(\varepsilon)}{\partial z} \varepsilon
$$




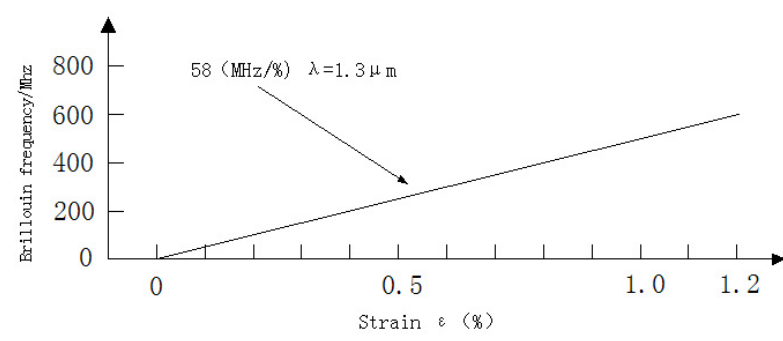

Figure 1. Strain dependence of Brillouin frequency shift change

where $\mathrm{V}_{\mathrm{B}}(\varepsilon)$ is the drift distance of Brillouin scattering light frequency when strain happens in optical fiber; $\mathrm{V}_{\mathrm{B}}(0)$ is the drift distance of Brillouin scattering light frequency when there's no strain in optical fiber; $\partial V_{B}(\varepsilon) / \partial \varepsilon_{\text {is proportionality coefficient which is about }}$ $0.5 \mathrm{GHz} / \%$ (strain); $\varepsilon$ is the axial strain of optical fiber. Compared with other scattering lights, another prominent advantage of Brillouin scattering light is that its association between frequency shift variation and temperature is much smaller than its association between frequency shift variation and strain $\left(0.002 \% /{ }^{\circ} \mathrm{C}\right)$. Thus, when measuring the Brillouin frequency shift related to strain, the influence of temperature on Brillouin frequency shift is often neglected when the temperature difference is under $5^{\circ} \mathrm{C}$.

Brillouin Optic Time Domain Reflectometer (BOTDR) is developed with optical light converging technology and Coherent detection technology, realizing the detection of Brillouin scattering light in high sensitive optical fiber with OTDR technology and Brillouin scattering technology. We can calculate the strain value of optical fiber according to the frequency variation value corresponding to the maximum intensity value of Brillouin scattering light before and after the strain on optical light. We can see from the principle that monitoring rock-soil body with BOTDR technology and placing optical fiber into monitoring object, and monitor the object comprehensively like implantation into "nervous system" (Wu et al, 2005).

BOTDR is a leading edge technology which has advantages as follows compared with traditional monitoring technology:

1) Distributed: On the end of optical fiber, we can get the information of stress, temperature, vibration and damage of any point. Regional and comprehensive monitoring of monitored object can be realized by mesh layout and decrease omission.

2) Long distance: This technology can monitor a distance of up to $80 \mathrm{~km}$, and optical fiber can not only serve as sensing element but also information transmission channel, which will help realize remote monitoring.

3) Adaptability: traditional geophysical engineer monitoring methods mostly use strain gage monitoring technology whose lifespan and veracity are greatly influenced by severe monitoring environment. The optical fiber is made of fiberglass, which is not only more durable than metallic material but also less disturbed by electromagnetism and thunder.

In this study, the BOTDR used is the newest AQ8603 optical strain analysis meter launched by Japanese Amtium Company. See major performance indexes in Table 1.

\section{Study area}

The highway from Guilin to Yangshuo stretches $66 \mathrm{~km}$ from Chongkou in Guilin in the north to Gaotian in Yangshuo and in the south via Lingui County, Yanshan District and Yangshuo County (Figure 2).

\begin{tabular}{|l|c|c|c|c|c|c|}
\hline \multicolumn{2}{|l|}{ Technical Index } & \multicolumn{5}{|c|}{ Optional parameter } \\
\hline \multicolumn{2}{|l|}{ Measured distance } & \multicolumn{2}{|c|}{$1,2,5,10,20,40,80 \mathrm{~km}$} \\
\hline Pulse width & $10 \mathrm{~ns}$ & $20 \mathrm{~ns}$ & $50 \mathrm{~ns}$ & $100 \mathrm{~ns}$ & $200 \mathrm{~ns}$ \\
\hline Dynamic range & $\pm 0.004 \%(2 \mathrm{~s})$ & $2 \mathrm{~dB}$ & $6 \mathrm{~dB}$ & $10 \mathrm{~dB}$ & $13 \mathrm{~dB}$ & $15 \mathrm{~dB}$ \\
\cline { 2 - 8 } & $\pm 0.003 \%(2 \mathrm{~s})$ & - & - & $8 \mathrm{~dB}$ & $11 \mathrm{~dB}$ & $13 \mathrm{~dB}$ \\
\hline Length resolution & $1 \mathrm{~m}$ & $2 \mathrm{~m}$ & $5 \mathrm{~m}$ & $11 \mathrm{~m}$ & $22 \mathrm{~m}$ \\
\hline Strain test accuracy & \multicolumn{2}{|c|}{$\begin{array}{c} \pm 0.004 \%(2 \mathrm{~s}) \\
( \pm 0.01 \%)\end{array}$} & \multicolumn{4}{|c}{$\begin{array}{c} \pm 0.003 \%(2 \mathrm{~s}) \\
( \pm 0.005 \%)\end{array}$} \\
\hline Strain test repeatability & \multicolumn{2}{|c|}{$<0.04 \%$} & \multicolumn{5}{|c}{} \\
\hline
\end{tabular}

Table 1. AQ8603(BOTDR)Technical Index 
The monitoring section is located between highway $\mathrm{K} 14 \sim \mathrm{K} 15$ which is the administrative region of Lingui County. This area is hoodoo plains geomorphic type with sea level elevation between 151 to $155 \mathrm{~m}$. The Quatemary soil system is slope and alluvial red clay. Soil composition is very heterogeneous and usually less than $5 \mathrm{~m}$ thick. The soil layer in the saturated zone is often soft and plastic, and may reach $10 \mathrm{~m}$. The bedrock is mainly Devonian-age dolomitic limestone of the Guilin Group, which has well-developed rock joints, fractures and karst (Figure 3).

The research area is located nearby subterranean rivers' discharge area where the underground waters are shallow and create seasonal wet land. The underground water is mainly karst underground water. Peak cluster area

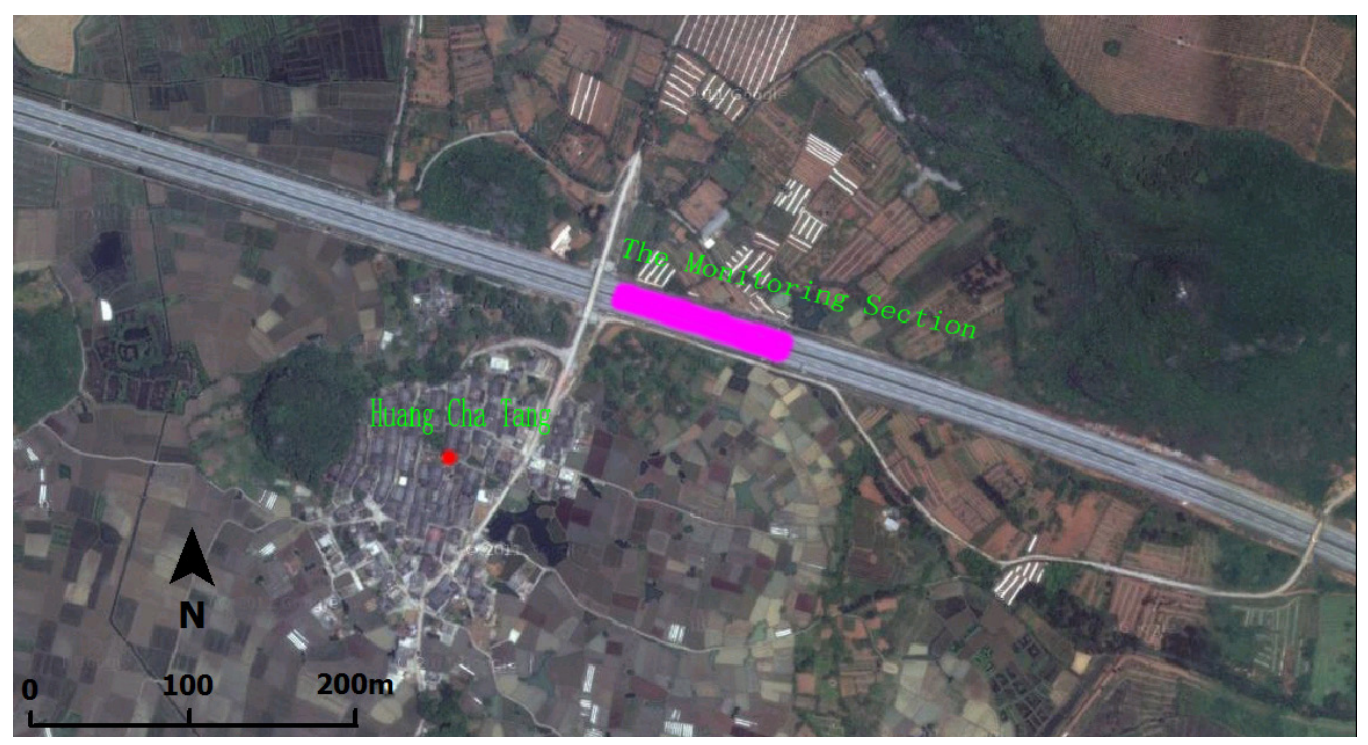

Figure 2. The location of the study area

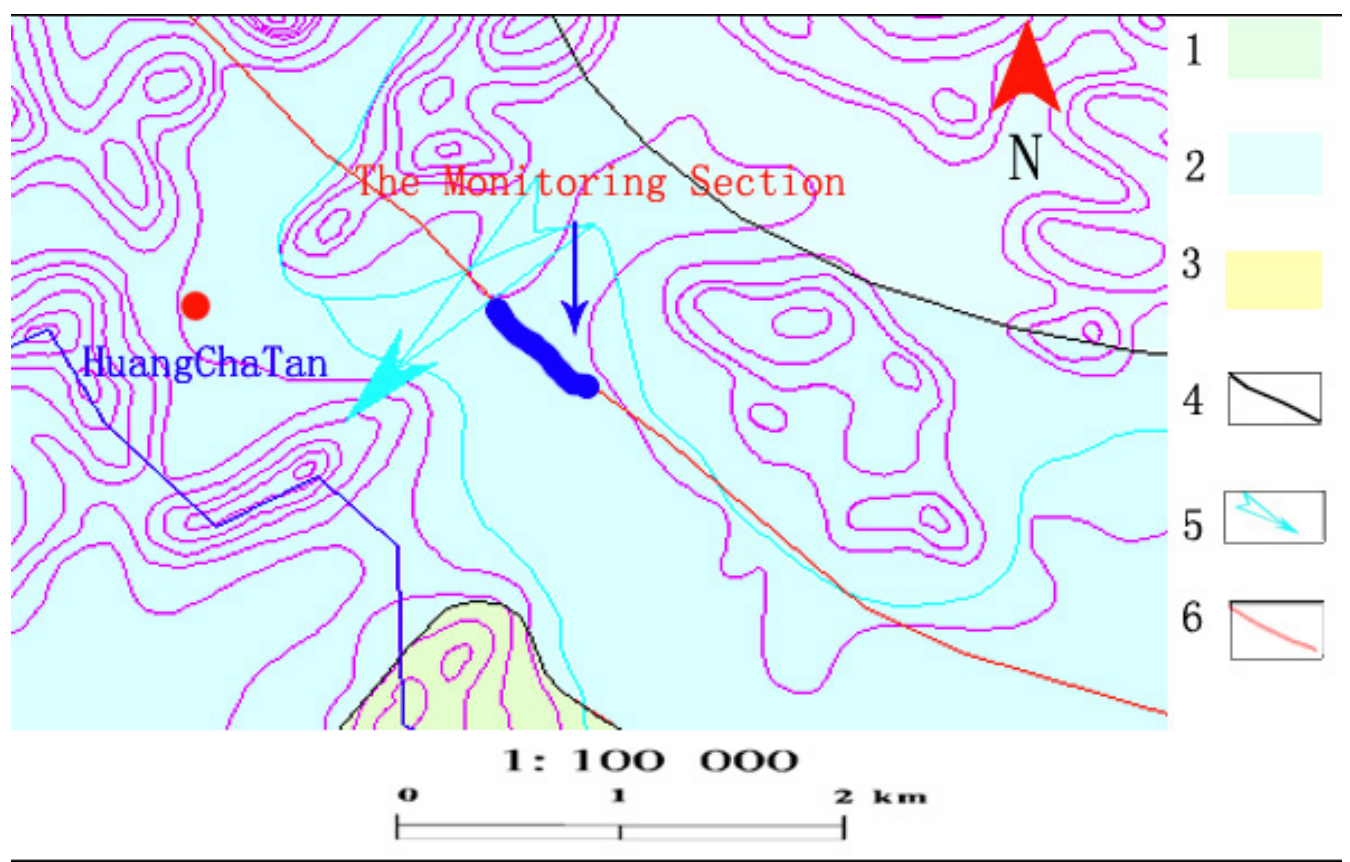

Figure 3. Location and geological map of the study area in Guilin City 1.limestone, 2.dolomite limestone, 3.alluvial red clay, 4.stratigraphic boundary, 5.the direction of groundwater flow, 6.the highway 
and hilly area receive water from atmosphere rainfall. Apertures are rich on the surface of bed rock and karst underground water has close relation with surface water.

\section{Technical proposal}

Karst caves grow in this area - there were 14 caves found in merely $100 \mathrm{~m}$ of the monitoring section. Engineering treatment was used in construction period. In order to prevent the influence of newly developed cave to the safe operation of the highway, this section was chosen to be the monitoring and early warning section of highway roadbed caves.

The monitoring length is $90 \mathrm{~m}$. The exploring application of this technology is done with the use of distributed optical fiber sensing technology to monitor and pre-warn about the roadbed caves under the highway. Through the analysis of the inbuilt environment's temperature, vibration and other elements' influence on monitoring results, by geological radar's scan to verify the reliability of monitoring result and finally present a security evaluation of this monitoring section.

\section{The selection of optical fiber types}

Generally, optical fiber contains fiber core, cladding, coating layer, restrictive coating, etc. Different structure and external bonding method will influence the sensitivity of measurement (Liu et al., 2006). Specific to working conditions like highway roadbed construction, according to existing conditions and experiments, the choice of Corning's single-mode tight tube optical fiber is ideal in practical application. Its major parameters are: core diameter/ cladding diameter/ tight tube diameter are $83 / 125 / 900 \mu \mathrm{m}$; maximum tension long-term 3.0N; minimum bending radius long-term $5.0 \mathrm{~cm}$; compressive strength $200 \mathrm{~N} / \mathrm{m}$; operating temperature $-20 \sim+80^{\circ}$; operating wavelength $1.3 \sim 1.5 \mu \mathrm{m}$; refractive index difference: $0.36 \%$; effective group refractive index: 1,4681 (1550 window).

\section{Laying scheme of roadbed optical fiber}

At present, there are several laying methods of optical fiber: fixed point bonding, $\Omega$ shape fixed point bonding and comprehensive fixed bonding. According to the operating condition of this project, through many experimental comparisons, the method of excavated cement mortar bonding optical fiber is chosen. Firstly excavate and lay certain thickness of cement mortar. Then pouring in proper cement mortar after optical fiber is placed in. Finally a cement beam is formed along the optical fiber and roadbed filling can be done.

Lay 4 parallel optical fibers along the roadbed. Record the locations and lengths of the optical fibers in detail and introduce them into monitoring box to supervise. Due to the severe operating environment, 4 break points appeared in the process of subgrade compaction after the optical fibers are laid. See Figure 4 for the locations.

\section{Study and analysis on influencing factors}

In order to study the influence of factors like seasonal temperature fluctuation on highway and vibration (traffic passing) on strain of optical fiber, dynamic measurement was conducted from 2011 at intervals of 1-2 months. Chosen GX2 optical fiber as object of study, effective monitoring length was $90 \mathrm{~m}, \mathrm{~K} 14+660 \mathrm{~m}$ was corresponding to the $40 \mathrm{~m}$ of monitoring data, K14+570m was corresponding to the breakpoint on $130 \mathrm{~m}$. Monitor-

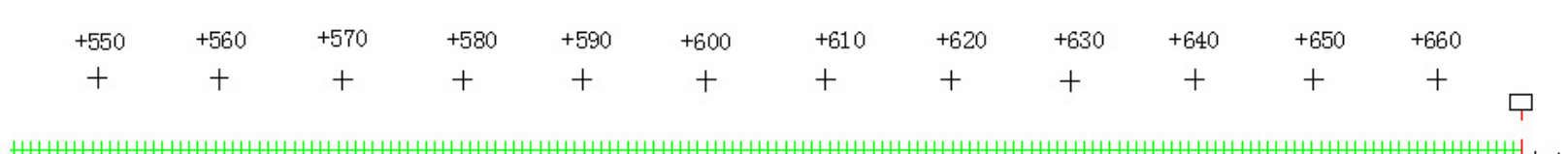

The elevation of embankment150.768m (optical fiber layer)

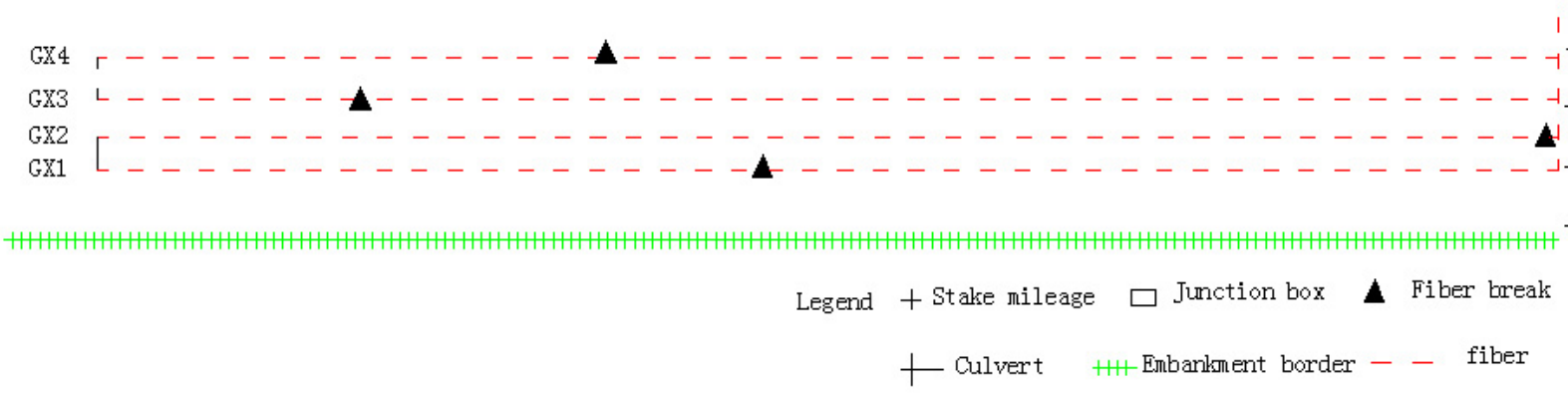

Figure 4. The optical fiber flat laying distribution. 
ing test items include: (1) the influence of environment temperature on the strain; (2) the influence of vibration on the strain.

\section{The influence of environment temperature on strain curve}

The monitored fracture surface is located in Guilin with low latitude and mid-subtropical monsoon climate. This area has a moderate climate, abundant rainfall, long frost-free season, ample light, rich heat, long summer and short winter, four distinctive seasons and rain heat during the same period. The annual average temperature is $17.8^{\circ}$. The hottest month is July, in which the average temperature is $28^{\circ}$; the coldest month is January, in which the average temperature is $5.8^{\circ}$.

Relevant research (Li et al, 2013) showed that filled subgrade temperature field has a hysteretic nature compared with atmosphere temperature field. Combined with the environment condition of Guilin, we took the data collected in January as basis reference, then compared and analyzed the data collected in March and August. Figure 5 is the difference value figure of the data collected in January of GX2 optical fiber under different environment temperature conditions.

Based on the principle of distributed optical fiber sensing technology, we can see that the offset of Brillouin scattering is influenced by not only axial strain of optical fiber but also temperature. For the Corning tight tube optical fiber used in this research, the influence of the changing temperature on Brillouin scattering light frequency spectrum offset is $1.43 \mathrm{~Hz} /{ }^{\circ} \mathrm{c}$, which is about $30 \mu \varepsilon$. The red bold line in the figure is the strain curve of the monitored optical fiber in August; the red fine line is the strain curve of the monitored optical fiber in March. The maximum strain difference is $200 \mu \varepsilon$; minimum difference is $10 \mu \varepsilon$, averagely $45.91 \mu \varepsilon$ higher and change rate is approximately $0.005 \%$, averagely $1.5^{\circ}$ of temperature change.
Optical fibers are laid $5 \mathrm{~m}$ under the roadbed. Within the scope of seasonal underground water fluctuation, the strain curve of optical fiber in high temperature season is mostly higher than the strain curve of optical fiber in low temperature season. Relevant research shows that the seasonal temperature variation change influenced by climate is large in subsurface temperature field influenced by phreatic fluctuation. And the temperature field change decreases apparently at $5 \mathrm{~m}$ (Li et al., 2013; Wu et al.,2010). Laboratory tests show that when temperature variation is less than $2^{\circ}$, the strain created by temperature can be omitted. Therefore, for this monitoring result, the influence of environmental temperature can be omitted.

\section{The influence of vibration on strain curve}

Different period of time has different number of vehicles passing by. According to observation on-site, 12:0013:00 is low ebb of traffic, and 15:00-16:00 is peak time of traffic. According to the observed data of two periods in a day, we analyzed the sensitivity of BOTDR on optical fiber vibration.

Taking GX2 as research section, we addressed the initial value of the observed data in peak time and low ebb of optical fiber circuit. We placed the two treated strain curves in Figure 6 and compared them.

We can see from Figure 4 that red line is a little bit higher than black line overall, which means that the monitoring curve in peak time is higher than its counterpart in low ebb. According to the figure, between $40 \mathrm{~m}$ and $55 \mathrm{~m}$, the strain is different; while after $55 \mathrm{~m}$, the differences of strain are minor, the two monitoring lines are almost identical. The average strain difference is $4.3 \mu \varepsilon$, that is to say, the vibration caused by passing vehicles has little influence on the result of optical fiber strain monitoring.

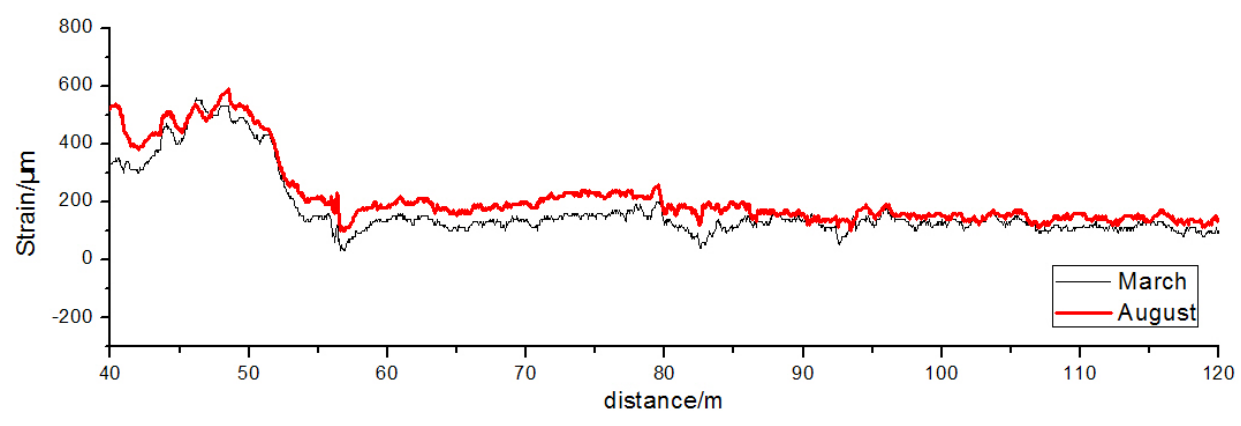

Figure 5. The different temperature environments of strain curves 


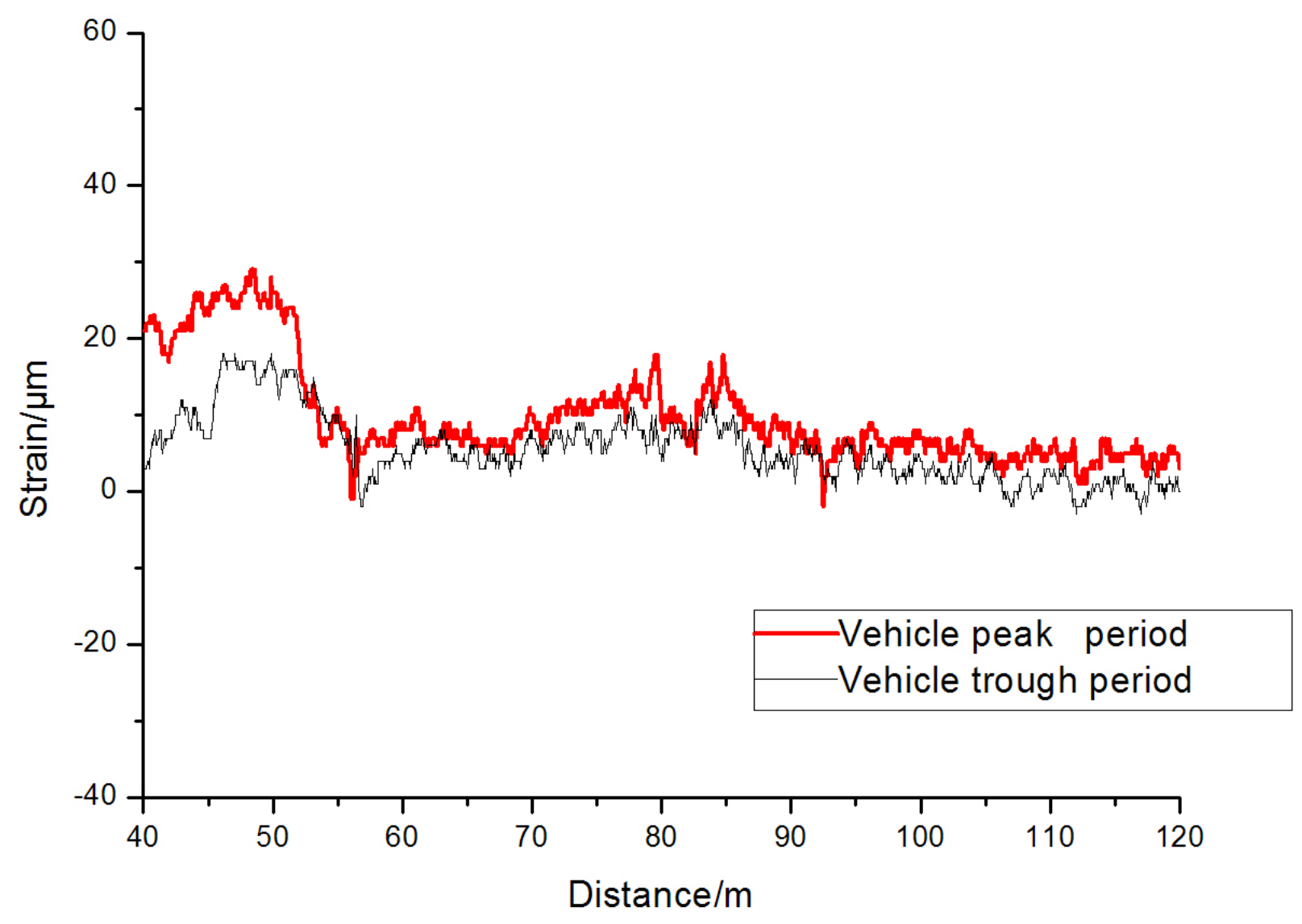

Figure 6. The comparison diagram of strain curves in peak time and low ebb of traffic in GX2 section

\section{Evaluation on the health of roadbed Analyses on the operation of monitoring data}

The monitored section of roadbed was laid 4 optical fiber, we took optical fiber GX2 for analysis. Long-term monitoring data shows that the monitoring of optical fiber tends to be stable after the stable period of construction (Figure 7).

The Figure below is the whole dynamic monitoring data of 2011. The data are all absolute strain value of GX2 optical fiber, of which $0-40 \mathrm{~m}$ is reserved section, 40-60 $\mathrm{m}$ is the section between monitoring box of optical fiber and $5 \mathrm{~m}$ underground, $60-130 \mathrm{~m}$ is the key monitoring section. Through the analysis, we can find that:

1) As is placed in monitoring box, 0-40 $\mathrm{m}$ has larger temperature fluctuation; 40-60 $\mathrm{m}$ is switch-in section which is influenced not only by environmental temperature because of its location in shallow ground but also temperature field change by seasonal water-level fluctuation due to its proximity to water culvert (the fluctuation of strain curve diminish from the near to the far); 60-130 is $5 \mathrm{~m}$ under- ground, which is less influenced by environmental temperature and is more identical with each other.

2) The test has shown that the strain caused by temperature under $2^{\circ}$ can be omitted. The average deviation of two strain curves who have the biggest discrepancy in a year is $1.5^{\circ}$, which can be omitted in this monitoring result.

\section{Geological radar scanning assessment}

Geological radar is a kind of geophysical prospecting using ultra high frequency electromagnetic wave to explore underground media. It can explore the developing status of karst cave down to $10 \mathrm{~m}$ effectively. Potential karst collapse can be prevented by regular scan.

The diagram below (Figure 8) is the geological radar exploring profile of the K14+550-K14+660 section of Guiyang highway in October 2011. Corresponding to GX2 optical fiber, the length of the scanning profile is $130 \mathrm{~m}$. it can be seen clearly from the diagram that there is no cave developing in this part of profile and the highway roadbed was operating safely. 


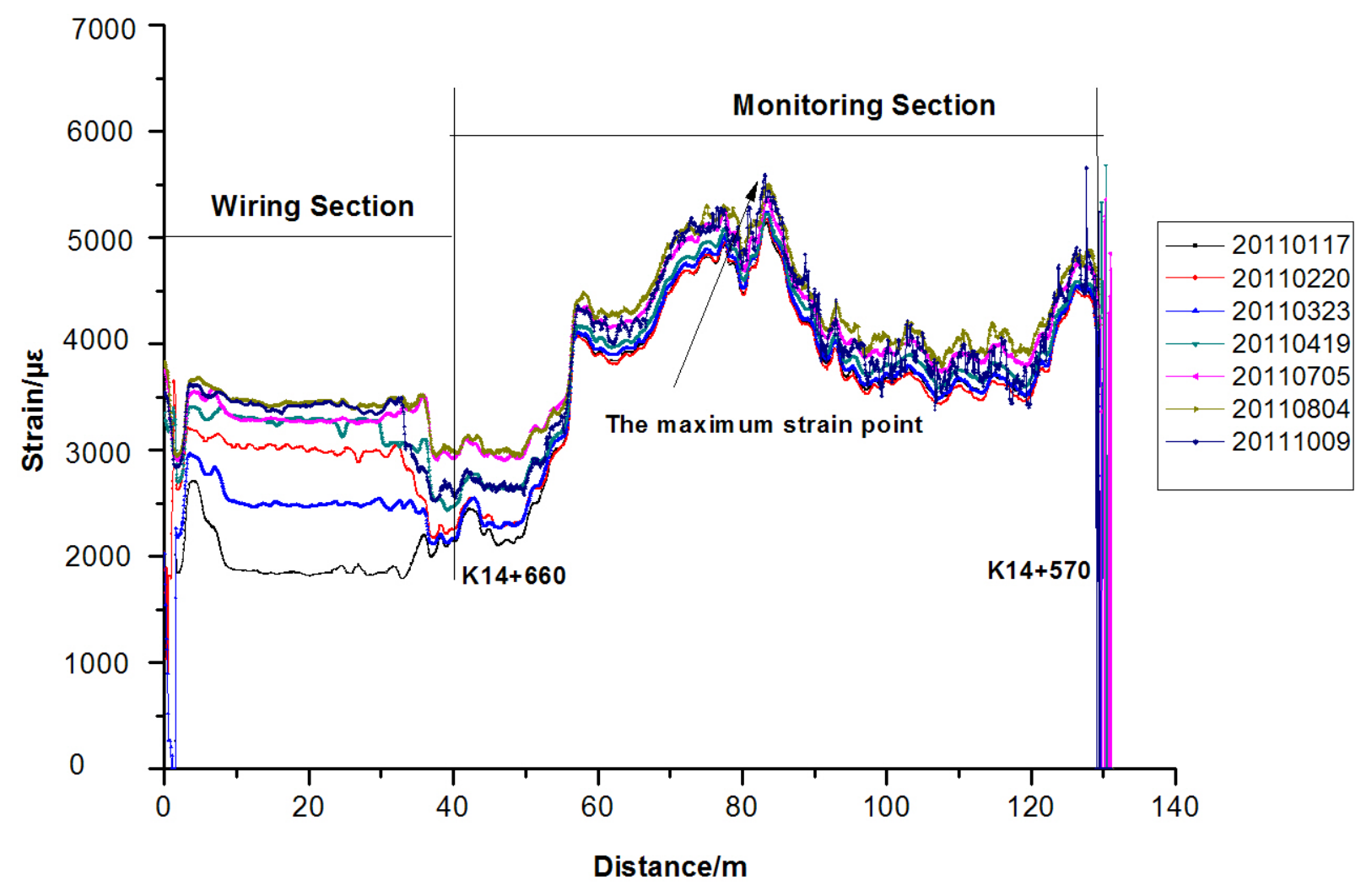

Figure 7. Strain curve of optical fiber GX2

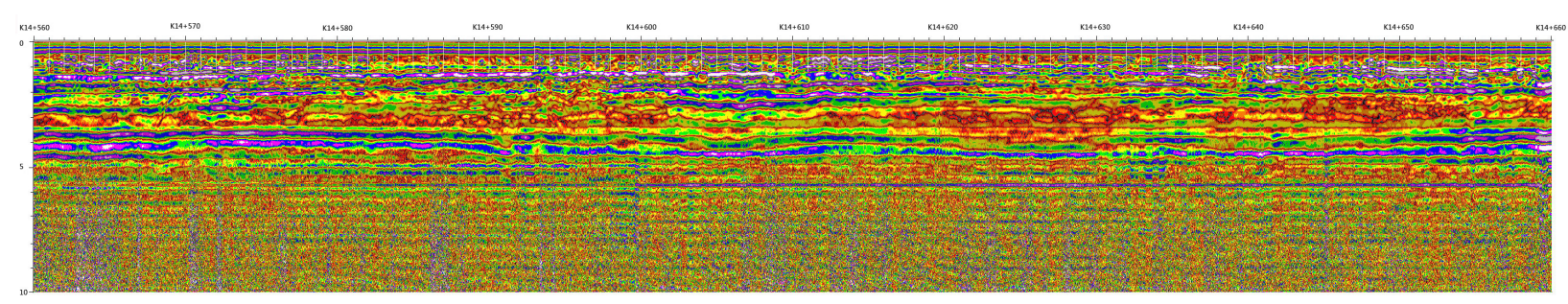

Figure 8. 3\# measuring line(corresponding to optical fiber GX2) result of geological radar exploring

The 4 optical fiber laid is under dynamic monitor by BOTDR technology. Except the seasonal entire change caused by temperature in reserved section and switch-in section, strain curves are mainly identical in key section with the overall average strain difference less than $0.03 \%$ which can be omitted. Meanwhile, by regular geological radar scanning, it is proved that there was no karst cave developing under the highway roadbed and the roadbed was healthy.

\section{Conclusion}

The health condition of highway roadbed is a most important index for the safe operation of roads. By laying distributed optical fiber monitoring system under test section of highway roadbed, we studied the change of strain field under roadbed with BOTDR technology. Optical fiber type and laying scheme were chosen according to on-site observation and experiments. The influence of environmental factors like temperature and vehicle vibrating load are analyzed. The result shows that the laying of distributed optical fiber monitoring system is successful and the influence of environment temperature and vehicles vibration on the monitoring result of strain field under roadbed can be omitted. Finally, we used geological radar to scan roadbed and further showed that the application of BOTDR technology is practical in roadbed health monitoring and has important application prospect. 


\section{References}

Assaf Klar, Raphael Linker. 2010. Feasibility study of automated detection of tunnel excavation by Brillouin optical time domain reflectometry. Tunnelling and Underground Space Technology 25: 575-586.

Haruyoshi UCHIYAMA, Yasushi SATO, ZhiXien LI. 1997. AQ8602 Optical Fiber Strain/Loss Analyzer. Ando Technical Journal.

Jiang X, Lei M, Chen Y, Ge J. 2006. An experiment study of monitoring sinkhole collapse by using BOTDR optical fiber sensing technique. Hydrogeology \& Engineering Geology 6: 75-80.

Li Zhe, Zhao ZuoFu, Xing YanRu. 2013. Contrastive Analysis on Temperature Field of Embankment and That under Nature Ground Surface. Subgrade Engineering 169 (4): 125-129.

Linker R, Klar A. 2009. Detection of sinkhole formation via Brillouin Optical-Fiber Time-Domain Reflectrometry(BOTDR). Geophysical Research Abstracts, Vol. 11, EGU2009-366. EGU General Assembly.

Liu J, Li Z. 1998. SM UL TANEO measurements of strain and temperature in smart structures using fiber grating and raman scattering. Acta Aeronautica et Astronautica Sinica 19 (7(S)).

Liu De-Hua, Jin L, Zhang X-Y. 2006. Strain transfer relationship between optical fiber sensor and structure matrix. Journal of Zhejiang University (Engineering Science). 40 (11): 1847-1851.

Shi B, Xu X, Wang D, et al. 2005. Study on BOTDRbased distributed optical fiber strain measurement for tunnel health diagnosis. China Journal of Rock Mechanics and Engineering 24 (15): 2622-2628.

Wu Z, Shi B, Harada T, et al. 2005. An experimental study on the measuring characteristics of BOTDR for structure health monitoring. China Civil Engineering Journal 38 (8): 56-73.

Wu ZhiWei, Song anZhou.2010.Numerical simulation of thermal convection in shallow ground temperature field. ROCK AND SOIL MECHANICS 31 (4): 1303-1308.

Xu HZ, Zhou Yuan, Zhang Dan. 2011.Development of karst collapse monitoring system using distributed optical fiber sensor based on GIS. HYDROGEOLOGY \& ENGINEERING GEOLOGY 38 (3): 120-123.

Zhang G, Jiang F. 2009.Monitoring sinkhole collapse by using optical fiber sensing technique of long gang central town, Shen Zhen City. Journal of Geological Hazards and Environment Preservation. 20 (4): 117-121. 